\title{
Factors contributing to high prevalence of gastrointestinal parasites in children aged 2-15 years in the Punta Cana region of the Dominican Republic
}

\author{
This article was published in the following Dove Press journal: \\ Reports in Parasitology \\ 16 December 2014 \\ Number of times this article has been viewed
}

\section{Kristin Anne Geers Childers James R Palmieri}

Department of Microbiology, Infectious and Emerging Diseases, Edward Via College of Osteopathic Medicine-Virginia Campus, Blacksburg, VA, USA
Correspondence: James R Palmieri Biomedical Research Faculty, Edward Via Virginia College of Osteopathic Medicine, 2265 Kraft Drive, Blacksburg,

VA 24060, USA

Tel +I 54023 I 4823

Email jpalmieri@vcom.vt.edu

\begin{abstract}
The prevalence of gastrointestinal parasites and the severity of infection have a profound impact on human health and development, affecting approximately one-third of the world's population. Gastrointestinal diseases, most notably caused by a variety of gastrointestinal parasites, are endemic to the Dominican Republic. A previous study demonstrated a $99.2 \%$ prevalence rate in children between the ages of 2 years and 15 years. The purpose of this study is to note the critical factors contributing to the high rate of gastrointestinal parasitic infections in children in the Punta Cana region of the Dominican Republic. This report addresses qualitative observations and contributory factors responsible for the high rate of gastrointestinal parasite infection. These factors include the impact of malnutrition, the role of weaning foods and caretaker food preparation in parasite transmission, the effects of contaminated water sources, sewage control, and lack of health education regarding prevention, control, and treatment of diseases. Prevention programs should be directed at both the national and the local levels, particularly in schools, for education in symptom recognition, prevention, and treatment. It is imperative that health care workers be trained in the use of new tools to help in estimating the prevalence of gastrointestinal parasites in both urban and rural settings. Parasitic infections affect growth, intelligence quotient, and nutrition-health and cause diarrhea, fatigue, dyspepsia, and anemia, resulting in high morbidity and mortality in children in this region of the Dominican Republic.
\end{abstract}

Keywords: clean water, Dominican Republic, gastrointestinal parasites, Haitian, nutritional, parasitic, Verón, weaning foods

\section{Introduction}

The Dominican Republic (DR) is located on the eastern portion of the Caribbean island of Hispaniola. It shares its landmass with the country of Haiti, which occupies the western one-third of the island. Spanish is the official language although English, French, and Haitian Creole are spoken by many rural and immigrant inhabitants. The estimated population is approximately 10 million. Life expectancy is estimated at 72.8 years, with $33.8 \%$ of the population considered to be in general poverty and $10.4 \%$ in extreme poverty. ${ }^{1-7}$ With the Atlantic Ocean to the north and the Caribbean Sea to the south, the DR abides in a tropical climate with a mean annual precipitation of $2.1 \mathrm{~m} .^{2,3}$

The rural city of Verón is located on the eastern tip of the island in La Alta Grácia province; close to the resort city of Punta Cana. The population of Verón is estimated 
at 8,000 and is made up mostly of migrant families with an average length of residence of 6 years. ${ }^{8}$ The major sources of income for people in the Verón area are highway development, construction, and the tourist industry centered in resorts along the coastline. The workforce consists of Dominicans and immigrants, many from Haiti. ${ }^{9}$ Some areas of Verón are partly shantytowns, which include irregular, low-cost dwellings, usually located at the outer edges of the city. Other parts of Verón are more urbanized, with neighborhoods, apartments, and gated communities. ${ }^{10}$ The majority of inhabitants in the poorer areas of Verón are uninsured and without access to public and private health care. Many rely on the outpatient medical care clinic, la Clínica Rural de Verón, for their medical needs. ${ }^{8}$ The children of Verón are at high risk for a variety of medical conditions, most notably for parasitic infections. ${ }^{1,9-14}$ In a comprehensive study by Childers et $\mathrm{al}^{9}$ conducted at la Clínica Rural de Verón, 127 of 128 children between ages 2 years and 15 years were found to be infected with one or more gastrointestinal parasites. Besides poverty, other contributory factors enhance this outrageously high infection rate that directly impacts several aspects of childhood development. Some factors impacting the high prevalence include the following: ideal tropical climates for soil-dwelling parasites, substandard water quality, lack of proper human waste disposal, contaminated food sources and food products, weaning foods, parasite-induced chronic malnutrition, reduced immunity, and the lack of health education regarding prevention, control, and treatment of infections.

The prevalence of gastrointestinal parasites and severity of infection have a profound impact on human health and development, affecting approximately one-third of the world's population. ${ }^{9,15}$ Gastrointestinal diseases are endemic to the DR, most notably those caused by gastrointestinal parasites including nematodes (Ascaris lumbricoides, Enterobius vermicularis, Necator americanus, and Trichuris trichiura), cestodes (Taenia saginata and Taenia solium), and protozoa (Entamoeba histolytica and Giardia duodenalis). ${ }^{9}$ These data, which demonstrated a 99.2\% prevalence rate, are detailed in a survey of gastrointestinal parasites of the Verón area as reported in 2014 by Childers et al. ${ }^{9}$ According to the 2011 report by the Pan American Health Organization (PAHO) on the national burden of neglected tropical diseases for the DR, 871,000 preschool-aged children and 2.1 million school-aged children are considered the "at-risk" population. ${ }^{16}$

\section{Purpose}

The purpose of this commentary is to note the critical factors contributing to the high rate of gastrointestinal parasitic infections in children aged $2-15$ years in the Punta Cana region of the DR. The primary author of this study, $\mathrm{K}$ Childers, spent 6 months in Verón and in the impoverished surrounding villages, identifying parasitic infections in children brought to the Rural Clinic of Verón. The details of the parasite data have been reported in a separate study. ${ }^{9}$ This article addresses the qualitative observations and contributory factors responsible for the high infection rate of gastrointestinal parasites in children, many that were difficult to present statistically.

\section{Critical factors}

\section{Nutritional factors and weaning foods}

Parasitic infections in preschool- and school-aged children have a major impact on health due to nutritional factors detrimentally affecting physical growth. ${ }^{17}$ Infections caused by these parasites slow the mental and physical growth of children; have long-term effects on educational achievement; rob children of iron, protein, and other vital nutrients; and impact economic activity at both local and national levels. ${ }^{5}$ Chronic parasitic infections greatly impact the cognitive development of young children in the DR by diminishing the ability to learn, increasing memory loss, and lowering overall intelligence quotient (IQ) levels. It has been reported that children chronically infected with gastrointestinal parasites lose on average 3.75 IQ points for each intestinal parasite with which they are infected. ${ }^{5}$ Other morbidities associated with gastrointestinal parasitic infections include intestinal bleeding, anemia, malabsorption of nutrients, loss of appetite, chronic dyspepsia, vitamin A deficiency, protein calorie malnutrition, diarrhea, vomiting, and conditions that may require surgical intervention such as rectal prolapse or intestinal obstruction. . $^{5,10,18-21}$ Parasitic infections can complicate pregnancies and birth outcomes. ${ }^{5}$ In pregnant women, serious anemia from parasitic infections of the blood and gastrointestinal tract can be life threatening to the mother and the child. Furthermore, gastrointestinal parasites can deplete nutrients from the mother and cause low birth weight in developing infants. ${ }^{2,5}$

According to data from the 2007 Demographic and Health Survey by the PAHO, only $8 \%$ of infants in the DR were exclusively breastfed at 6 months of age. ${ }^{2}$ Contaminated weaning foods, or foods given to infants in transition from breast milk to solid foods, may account for a substantial portion of diarrheal diseases among infants and young children. ${ }^{19}$ The authors of this study could not find any published data that address what constitutes weaning foods for infants in the DR or how mothers prepare weaning foods. In a study of infants and children in a Guatemalan Mayan village, prevalence of 
many infections increased during and following the weaning period, with a particularly high incidence of diarrhea in children between 7 to 18 months old, peaking at 9 months; other studies have reported the prevalence of diarrhea being highest during the second 6 months of life. ${ }^{19}$ Sources of contamination of weaning foods include pests, domestic animals, wastewater, irrigation water, contaminated household water, night soil, infected food animals, food handlers, dirty cookware, cross-contamination, and foods contaminated during cultivation. ${ }^{19}$ Biological contamination and the role of caregivers in preparing infant foods may have grave consequences for infants and children, ultimately resulting in higher morbidity and mortality. ${ }^{19}$

\section{Caretakers}

There is a wide range of caregivers for children in the DR, including older siblings, teachers, parents, guardians, and grandparents. The caretaker plays an important role in the transmission of gastrointestinal parasitic infections to children in the DR. In a poor periurban community of Santo Domingo, DR, 582 caregivers of children aged less than 5 years from four neighborhoods were sampled for a study. ${ }^{22}$ Results showed that $55 \%$ of caregivers did not boil drinking water for children, 38\% did not always wash the hands of the children prior to meals, $87 \%$ of children did not always wear shoes outside their houses, and $54 \%$ of infants were breastfed for less than 1 year. ${ }^{22}$ Often in the DR, "forgetfulness" is given as the excuse for the above factors. In addition, erroneous beliefs and cultural misconceptions of caregivers may play a significant role in increasing caregiver-caused gastrointestinal parasitic infections. For example, it is believed by some adults that children may become sick if they begin consuming purified water after drinking untreated water. ${ }^{22}$

\section{Clean water and sewage control}

There is a strong association between poverty and the prevalence and intensity of parasitic infections. ${ }^{23}$ Gastrointestinal parasitic infections are closely interwoven with poor sanitation, lack of safe water, and inadequate disposal of human excreta. $^{16}$

Without fundamental services such as clean water and sanitation, communicable diseases continue to have a significant presence in the DR, resulting in many diseases among children. Consequently, communicable diseases presenting as diarrhea and respiratory symptoms account for $61 \%$ of all mortality in Dominican children. ${ }^{20}$ A study in Porto Plato, $\mathrm{DR}$, examined the relationship between microbial drinking water quality and water sources. The study analyzed data from 409 households in 33 communities. Results showed that $47 \%$ of "improved drinking water sources" were of a high- to very-high-risk water quality and therefore deemed unsafe to drink. ${ }^{24}$ Thus, although a water quality analysis may be deemed "improved," it still may be at high risk for microbial contamination. ${ }^{12,24}$ It is understandable that local inhabitants think that they are drinking pathogen-free water, where in fact, this is often not the case.

Throughout Verón and neighborhoods located at the periphery of the city, open-pit public toilets are common. ${ }^{9,10}$ The PAHO has estimated that $<50 \%$ of those living in rural areas of the DR have access to clean drinking water and only $16 \%$ have sanitary sewage disposal services. These factors of poor sanitation and water quality contribute to approximately $95 \%$ of deaths in children younger than 5 years of age in the DR. ${ }^{15,19,25}$

\section{Potential solutions at the national and international levels}

In a comprehensive report by the PAHO on the prevalence and intensity of soil-transmitted helminths in Latin America and Caribbean countries, data collected between 2000 and 2010 revealed the absence of any major or comprehensive published reports for the DR. This is in great contrast to neighboring Haiti, for which several definitive publications exist even though both Haiti and the DR share the same island. ${ }^{2}$ It is imperative that health care workers be trained in the use of new tools to help in estimating the prevalence of gastrointestinal parasites in both urban and rural settings. These workers will require appropriate software and equipment to access databases and to make meaningful predictions on prevalence and incidence of diseases, allowing for estimations at any time and any place by researchers, health care workers, and policymakers. ${ }^{2}$

There is a great need for public health programs to identify, treat, control, and prevent infection by gastrointestinal parasites. Any major health initiative within the DR must take into account the following: the impact of parasitic burden on morbidity and mortality of children, the communicability of parasitic infections as it relates to parasite burden (the more parasites in the infected individual, the greater is the capacity to transmit the infection), and the ability to measure burden and prevalence of infections. ${ }^{21}$ Any successful control program requires a combination of communication, social mobilization, economic support, health education, community participation, and drug therapy. ${ }^{21,22}$

It is necessary to encourage operational research agendas within governments, the public, and community 
interest groups in the DR in order to develop parasite prevalence and incidence mapping activities. ${ }^{2}$ Mapping is necessary to know where the populations at risk are located and those who are most at risk of infection. Mapping allows authorities to focus their evaluation, monitoring, and treatment programs. ${ }^{2}$ Parasitic worms disproportionately affect the most disadvantaged, particularly in urban and rural areas, and trap vulnerable people in a cycle of poverty. ${ }^{4}$ Interventions are necessary to prevent and control gastrointestinal parasitic infections. There is an immediate need to educate parents, teachers, and health care providers with information on balanced diets and pathogen-free food preparation to improve the overall health of children and their ability to learn and to contribute to society in a more productive manner.

\section{Conclusion}

Gastrointestinal parasitic infections are a major cause of morbidity and mortality in the DR. The report by Childers et $\mathrm{al}^{9}$ on children in Verón demonstrates the major factors responsible for an infection prevalence rate of $99.2 \%$ with at least one or more gastrointestinal parasites. These parasitic infections affect growth, IQ, and nutrition-health and cause diarrhea, fatigue, dyspepsia, and anemia, resulting in high morbidity and mortality in children in this region of the DR. Modes of transmission of gastrointestinal parasites include water, food, caregivers, pests, excreta, and cross-contamination. Infants are particularly vulnerable during the weaning period. Prevention programs should be directed at both the national and the local levels, particularly in schools, for education in symptom recognition, prevention, and treatment of infection.

\section{Disclosure}

The authors report no conflicts of interest in this work.

\section{References}

1. Hotez PJ. Holidays in the sun and the Caribbean's forgotten burden of neglected tropical diseases. PLoS Negl Trop Dis. 2008;2(5):e239.

2. Pan American Health Organization. Health in the Americas 2012 Edition-Regional Outlook and Country Profiles. Washington, DC: PAHO; 2012:112-115. [ISBN 978-92-75-11691-3: Dominican Republic].

3. Index Mundi. Factbook, Countries, Haiti, Demographics. [Cited March 20, 2014]. Available from: http://www.indexmundi.com/haiti/literacy. html. Accessed November 18, 2014.

4. Office of Public Affairs, Central Intelligence Agency, Washington, DC 20505. The World Factbook Library. [Cited March 20, 2014]. Available from: https://www.cia.gov/library/publications/the-world-factbook/ fields/2103.html. Accessed November 18, 2014.

5. The Global Network for Neglected Tropical Diseases, IDB, PAHO. A Call to Action: Addressing Soil-transmitted Helminths in Latin America and the Caribbean. Washington, DC: Inter-American Development Bank, PAHO, Sabin Vaccine Institute; 2011.
6. Gates HL. Black in Latin America: The Dominican Republic, Black behind the Ears. Chap 4. New York: NYU Press; 2011:119-145.

7. Gyapong JO, Gyapong M, Yellu N, et al. Integration of control of neglected tropical diseases into health-care systems: challenges and opportunities. Lancet. 2010;375(9709):160-165.

8. Scarpaci JL. Plazas and Barrios: Heritage Tourism and Globalization in the Latin American Centro Histórico. Tucson, AZ: University of Arizona Press; 2005.

9. Childers K, Palmieri J, Sampson M, Brunet D. A survey of the prevalence of gastrointestinal parasites in children From Verón: a rural city of the Dominican Republic. Res Reports Trop Med. 2014;5:45-53.

10. Sasidharan V, Hall ME. Dominican resort tourism, sustainability, and millennium development goals. J Tourism Insights. 2012;3(1):5.

11. Vermund SH, LaFleur F, MacLeod S. Parasitic infections in a New York City hospital: trends from 1971 to 1984. Am J Public Health. 1986;76(8):1024-1026.

12. Mackie TT, Larsh JE, Mackie JW. A survey of intestinal parasitic infections in the Dominican Republic. Am J Trop Med Hyg. 1951; 31(6):825.

13. Collins RF, Edwards LD. Prevalence of intestinal helminths and protozoans in a rural population segment of the Dominican Republic. Trans R Soc Trop Med Hyg. 1981;75(4):549-551.

14. World Health Organization. Intestinal protozoan and helminthic infections. Geneva: World Health Organization; 1981. Available from: http:// apps.who.int/iris/bitstream/10665/41519/1/WHO_TRS_666.pdf?ua=1. Accessed November 18, 2014.

15. Pan American Health Organization Communicable Disease Prevention and Control Project. Prevalence and intensity of infection of Soiltransmitted Helminths in Latin America and the Caribbean Countries: mapping at second administrative level 2000-2010. Washington, DC: PAHO c; 2011.

16. Neglected Diseases profile: Dominican Republic. [Cited April 16, 2014]. Available from: http://www.neglecteddiseases.net/wp-content/ themes/tropical/pdf/Country-profile-DominicanRepublic.pdf. Accessed November 18, 2014.

17. Regional Office for the Americas of the World Health Organization, Washington DC. United States of America. Meetings report: Framework for a Regional Program for Control of Soil-Transmitted Helminth Infections and Schistosomiasis in the Americas. Santo Domingo, Dominican Republic; June 26, 2003.

18. Ramana KV. Intestinal parasitic infections: an overview. Ann Trop Med Public Health. 2012;5(4):279.

19. Motarjemi Y, Käferstein F, Moy G, Quevedo F. Contaminated weaning food: a major risk factor for diarrhoea and associated malnutrition. Bull World Health Org. 1993;71(1):79.

20. Carman SK, Scott J. Exploring the health care status of two communities in the Dominican Republic. Int Nurs Rev. 2004;51(1):27-33.

21. Grady C, Younos T. Water use and sustainability in La Altagracia, Dominican Republic. VWRRC SR49-2010. Blacksburg, VA: Virginia Tech; 2010.

22. McLennan JD. To boil or not: drinking water for children in a periurban barrio. Soc Sci Med. 2000;51(8):1211-1220.

23. Kurup R, Hunjan GS. Intestinal parasites in St Lucia: a Retrospective Laboratory-Based Study. J Rural Trop Public Health. 2010;7(9): 24-30.

24. Baum R, Kayser G, Stauber C, Sobsey M. Assessing the microbial quality of improved drinking water sources: results from the Dominican Republic. Am J Trop Med Hyg. 2014;90(1):121-123.

25. Periago MR, Frieden TR, Tappero JW, De Cock KM, Aasen B, Andrus JK. Elimination of cholera transmission in Haiti and the Dominican Republic. Lancet. 2012;379(9812):e12-e13. 
Reports in Parasitology

\section{Publish your work in this journal}

Reports in Parasitology is international, peer-reviewed, open access journal publishing original research, reports, reviews and commentaries on all areas of parasitology. The manuscript management system is completely online and includes a very quick and fair peer-review

Submit your manuscript here: http://www.dovepress.com/reports-in-parasitology-journal

system. Visit http://www.dovepress.com/testimonials.php to read real quotes from published authors. 